\title{
Reframing Disability as Competency: Unpacking Everyday Technology Practices of People with Visual Impairments
}

\author{
Gisela Reyes-Cruz, Joel E. Fischer, Stuart Reeves \\ Mixed Reality Laboratory, School of Computer Science \\ University of Nottingham, UK \\ \{aurea.reyescruz, joel.fischer, stuart.reeves\}@nottingham.ac.uk
}

\begin{abstract}
More than a billion people in the world live with some form of visual impairment, and a wide variety of technologies are now routinely used by them in the course of 'getting on' in everyday life. However, little is known about the ways in which assistive and non-assistive technologies are brought to bear on material practices. We present findings from a fourmonth ethnographic study facilitated by a local branch of a UK charity that supports people with visual impairments. Our study explores mainstream and assistive technology use within their everyday lives. We identify three main sites for technology use: social relations and communication practices, textual reading practices, and mobility practices. Via an ethnographic approach we contribute to understanding how people accomplish such practices, and in doing so, uncover the practical competencies that enable people with visual impairments to conduct their everyday activities. Thus we investigate how disability can be thought of in terms of competencies, arguing that understanding of competencies can enrich the design of technologies that fit the needs of people with visual impairments.
\end{abstract}

\section{Author Keywords}

visual impairments; disability; ethnography; ethnomethodology; assistive technology.

\section{CSS Concepts}

- Human-centered computing; Empirical studies in accessibility

\section{INTRODUCTION}

For the last two decades there has been a significant growth of interest by HCI in the field of Assistive Technology (AT) for people with visual impairments (VI) [8]. AT research has studied both the nature of disabilities, and the design, development, and evaluation of technologies to assist and support people through the difficulties they experience, and for improving their quality of life (e.g. [8,29,50]). Despite these efforts, people with VI still experience physical, social, infrastructural and accessibility barriers

This is the author's version of the work. It is posted here for your personal use. Not for redistribution. The definitive version will be published:

https://doi.org/10.1145/3313831.3376767

CHI 2020, April 25-30, 2020, Honolulu, HI, USA

(C) 2020 Copyright is held by the owner/author(s). Publication rights licensed to ACM. ACM ISBN 978-1-4503-6708-0/20/04 ...\$15.00. in their everyday lives. Complicating matters is the fact that there are noticeable differences between and within groups of people with visual impairments (e.g. low vision and blind) that consequently affect use of AT and technologies in general. Yet, such differences are not always acknowledged by AT design, resulting in cumbersome or unsuccessful interactions [5,36]. We argue that the differences in such impairments occasion situational, local practices that are leveraged by visually impaired people to 'get on' in everyday life.

Prior work has investigated low tech (e.g. magnifier lens, Braille notetaker) and high tech (e.g. smartphones, apps) artefacts used by people with VI in their everyday activities [56]. Some studies focused on specific apps [3,11,62], websites [34,59], or devices [1,13,30,42], asked participants to carry out pre-defined tasks, and ultimately found and/or confirmed continuing accessibility challenges. Prior work has also investigated people's practices in their everyday life, such as social and professional interactions [49,55], demonstrations and discussions of technology use [48] and creation and maintenance of accessible spaces $[7,10,30]$. We build upon such qualitative research. We adopt an ethnographic approach (with ethnomethodological orientation) to develop enriched accounts of the lifeworld of people with VI that otherwise might remain unnoticed or taken for granted. Our focus builds on calls for centring design on ability rather than disability $[40,63]$ (although we do not wish to imply an erasure of 'disability'). Our goal in this paper is thus to extend and expand upon this by examining everyday practices of people with VI including communication work, reading, and mobility.

Our study involved four months of ethnographic fieldwork with members of a charity that supports people with VI. The study comprised research observation at group meetings, one-on-one interviews, and observation of technology use at home and at work. In this paper we contribute to the body of knowledge of VIs and AT by 1) looking towards what ethnomethodology can offer for AT by examining the thoroughly practical, 'mundane' activities of people with VI; 2) describing these practices where the use of technology is embedded and how these are brought off; and 3) based on these observations, documenting the various competencies that participants demonstrate while undertaking their practices. This is, however, a broad study in which we did 
not seek to focus on a specific matter but rather obtain a holistic perspective of participants' lives.

\section{VISUAL IMPAIRMENT, DISABILITY AND TECHNOLOGY}

Here we review research on technologies design for use by people with visual impairments, critiques of design orientations towards visual impairments and broader notions of disability, and ethnomethodological approaches.

\section{Technology use by visually impaired people}

There have been decades of research into accessible technologies. This has examined visually impaired peoples' use of desktop computers, mobile devices and screen readers $[18,30,32,53,60,64]$. Accessibility issues of websites and applications also have been widely investigated $[14,32,56]$. Recent studies have started to examine use of mainstream voice assistants [1,18,42] and head mounted displays [66].

A large and longstanding body of literature has also investigated outdoor and indoor navigation and wayfinding [8,24], whilst some research has also investigated other specific activities around technology. Prior work has also examined people with VI's practices in everyday life, such as social and professional interactions [49,55], demonstrations and discussions of technology use $[2,48]$ and creation and maintenance of accessible spaces [7,10,30,60].

Generally, prior research has found that people with VI employ a range of methods, strategies, workarounds or configurations for overcoming accessibility issues encountered or for adapting to their environment, such as appropriating the phone's camera as magnifier $[2,53,60]$, placing markers on objects in order to find and identify them [10], or requesting co-located or remote assistance $[3,5,33,54]$. These methods are strictly related to one's unique conditions and experiences. For instance, research has outlined explicit differences in interaction methods between and within low vision, blind, and people experiencing vision loss $[5,26,53,54,57,65,66]$. Oliveira et al. [36] also highlight different sensory, cognitive and motor capability levels among blind participants. However, these differences aren't always taken into consideration by design.

\section{Reframing disability for design purposes}

The social model of disability was introduced in the mid1970s. This argues that disability is not defined by personal impairments but by the barriers people face in society $[37,38]$, as opposed to a notion that disability exists only as a property of the individual (commonly known as the medical or individual model). The social model has served as an important framework for activism, helping to identify and eradicate some of those barriers (e.g. the creation of laws against discrimination, accessible buildings and transport), but nevertheless is not exempt of criticism [15,37]. Theorists and activists working on feminist disability studies $[23,27,47,61]$ and disability justice (e.g. [41]) have critiqued the social model arguing that exclusion or stigma falls upon "particular kinds of bodies, minds and ways of being" [27] and that the social model may neglect their relevance to the discussion. Thus, in this view, solely considering disability as a social construct becomes problematic and there is a need to consider both the embodied individual and structural (e.g. built environment, social patterns) factors that comprise, as a whole, the experience of disability.

Developments along these lines have also impacted technology design. For instance, Wobbrock et al. [63] proposed the Ability-Based Design framework, which comprises seven principles that orient designers to "what a person can do", moving the burden of adaptation from the user to the system. In contrast, Frauenberger [20] raised concerns of focusing on functional abilities as starting point of technological solutions. He proposed a critical realist perspective to guide the design of technology for people with disabilities, setting an agenda for the AT field that includes generating holistic understandings of disability. Our paper has been inspired in part by this line of work but also ethnomethodological research, which we outline next.

\section{Ethnomethodological studies of visual impairment}

We draw on a strand of ethnomethodological work that has focussed on the 'visible', accountable, locally produced, situated encounters of people with visual impairments. This work articulates the interactional order in which everyday activities are accomplished by using embodied and material resources. Here we survey two key works.

First we turn to Due and Lange's [17] work, which examined the use of white canes and guide dogs as extended resources (i.e. that help, facilitate or afford task solving) that blind participants leveraged when navigating urban areas. White canes can extend one's tactile and aural senses, to then help locate objects in the vicinity, and act as a symbolic resource for other pedestrians. Due and Lange also argue that guide dogs also provide such extended resources, as found in trusting the dog to make decisions and negotiate trajectories. Canes convey information about obstacle presence and dogs about safe routes. Their study reveals how ocular-centrism in urban environments has pervasive, deeply practical implications.

Secondly we draw on vom Lehn [31], who investigated how visually impaired people examine and experience art with sighted guides in public galleries. Findings suggest that provision of interpretative resources (e.g. labels, guides) is not enough to ensure social inclusion in museums. Visually impaired and sighted participants employed different "experiential styles" (e.g. skilled sensitive touch) when encountering artwork, thus creating shared experiences of the pieces was only successful when sighted guides aligned to visually impaired modalities (e.g. touching exhibits).

We think ethnomethodology's emphasis on situated competencies ([21], p. 57), in and as the "capability of managing one's everyday affairs without interference", has much to bring to research on disability and visual impairments in particular. For example, Garfinkel describes Helen, a woman with congenital night blindness, who 
configured the arrangement of cookware in her kitchen in just such a way that she may then competently and fluidly produce meals for her partner [22]. Critically, Helen's careful siting of various pots, pans and utensils in a specific spatial organisation on her wall is itself an account of the specific situational competencies she has developed in response to her condition.

Inspired by this, we examine participants' practices involving technology in the course of 'getting on' in everyday life and the ways in which their own configuration work and practices lay the groundwork for the development of different competencies. Instead of articulating visual impairments as 'problematic', we are more interested in uncovering - for the particular visual impairments our participants have-just how participants practically accomplish everyday activities, in much the same sense that 'anyone' must 'get on' with things so as to interactionally achieve mundanity.

\section{THE STUDY APPROACH AND SETTING}

Initial contact was established with staff members of the charity to discuss the viability of the study. They acted as gatekeepers for allowing the first author to immerse herself in the community, beginning with a Sight Loss Awareness and Sight Guide training for sighted volunteers, which included introductory information about different eye conditions and recommendations for communicating effectively with people living with visual impairments.

Subsequently, the researcher started attending group meetings at the charity office. They lasted between two and two and a half hours and had regular attendees. They mostly comprised older adults (over 60 years old), but there were also a few younger attendees, staff and volunteers (28 to 60 years old). Informal conversations and observation of some activities (e.g. training in the use of, and practice with, screen readers) were conducted to acquire a preliminary understanding of the setting, the people and their activities, and to build rapport with them. Up to this point, data collection consisted of field notes (no personal data).

In the following meetings, attendees were approached directly and invited to take part in interviews, arranged at the participants' preferred times and locations. No specific criteria were defined, except for being visually impaired. Preference was given to people who use technology regularly, but the study was not restricted to them, as we also wanted to explore the reasoning behind technology adoption, or, conversely, non-use $[33,39,44]$. Their informed consent was gained following ethical research guidelines, and an inconvenience allowance was provided to them for each session. The researcher continued attending group meetings to recruit more people until we considered that participant saturation was reached. However, these meetings were also used to elicit conversation about themes emerging in interviews and observations, and for expanding our understanding of the experiences of attendees.

\section{Participants and data collection}

In total, 11 participants were recruited for individual sessions: seven men and four women, aged between 28 and 93 years old (mean=52.5, SD=22.3) (see Table 1). All participants identified as legally blind, but they have different eye conditions. Some participants also described hearing, mobility or other sensorial impairments due to age or health conditions. All participants were interviewed in mixed settings about their everyday activities and technology use - or non-use-within them, and follow-up observations were conducted for 10 participants (see Table 1). We employed an open structure for the interviews and asked to observe activities that derived from talking to participants.

\begin{tabular}{|c|c|c|c|c|c|}
\hline$\#$ & $\mathrm{G}$ & Age & Eye Condition & IT/AT devices & Data Collection \\
\hline P1 & M & 28 & $\begin{array}{l}\text { Partially } \\
\text { sighted } \\
\text { (Glaucoma) }\end{array}$ & $\begin{array}{l}\text { iPhone, wireless } \\
\text { keyboard, } \\
\text { magnifying } \\
\text { spectacles }\end{array}$ & $\begin{array}{l}\text { Interview }(1 \mathrm{hr}) \text { and } \\
\text { observation }(1 \mathrm{hr}) \text { at } \\
\text { the charity office }\end{array}$ \\
\hline $\mathrm{P} 2$ & $\mathrm{M}$ & 50 & Blind & iPhone, iPad & $\begin{array}{l}\text { Interview at the } \\
\text { charity office }(1 \mathrm{hr}) \text {, } \\
\text { observation at home } \\
(3 \mathrm{hr})\end{array}$ \\
\hline P3 & $\mathrm{M}$ & 32 & $\begin{array}{l}\text { Partially } \\
\text { sighted }\end{array}$ & $\begin{array}{l}\begin{array}{l}\text { iPhone, } \\
\text { keyboard, } \\
\text { watch }\end{array} \\
\end{array}$ & $\begin{array}{l}\text { Interview at the } \\
\text { charity office }(1 \mathrm{hr})\end{array}$ \\
\hline P4 & M & 93 & $\begin{array}{l}\text { Partially } \\
\text { sighted } \\
\text { (Cataracts) }\end{array}$ & $\begin{array}{lr}\text { Doro } & \text { phone, } \\
\text { pocket } & \text { magnifier, } \\
\text { lamp } & \text { magnifier, } \\
\text { talking } & \text { watch }\end{array}$ & $\begin{array}{l}\text { Interview and } \\
\text { observation at home } \\
(4 \mathrm{hr})\end{array}$ \\
\hline P5 & W & 28 & Blind & $\begin{array}{l}\text { iPhone, Windows } \\
\text { laptop and desktop } \\
\text { computer, } \\
\text { electronic Braille } \\
\text { note taker, audio } \\
\text { labeller }\end{array}$ & $\begin{array}{l}\text { Interview at the } \\
\text { charity office ( } 1 \text { hr), } \\
\text { observation at home } \\
\text { ( } 3 \text { hr), observation at } \\
\text { reception desk ( } 1.5 \\
\text { hr) }\end{array}$ \\
\hline P6 & $\mathrm{M}$ & 55 & $\begin{array}{l}\text { Partially } \\
\text { sighted }\end{array}$ & $\begin{array}{ll}\text { Samsung } & \text { phone, } \\
\text { Windows desktop } \\
\text { computer, } \\
\text { electronic } \\
\text { magnifier }\end{array}$ & $\begin{array}{l}\text { Observation } \\
\text { reception desk }(1.5 \\
\text { hr) }\end{array}$ \\
\hline P7 & $\mathrm{M}$ & 67 & $\begin{array}{l}\text { Partially } \\
\text { sighted }\end{array}$ & $\begin{array}{l}\text { Samsung phone, } \\
\text { radio for the blind, } \\
\text { Amazon echo }\end{array}$ & $\begin{array}{l}\text { Interview and } \\
\text { observation at home } \\
(3 \mathrm{hr})\end{array}$ \\
\hline P8 & $\mathrm{M}$ & 40 & Blind & $\begin{array}{lr}\text { Doro } & \text { phone, } \\
\text { Windows } & \text { desktop } \\
\text { computer, talking } \\
\text { watch }\end{array}$ & $\begin{array}{l}\text { Observation } \\
\text { reception desk }(1.5 \\
\text { hr) }\end{array}$ \\
\hline P9 & W & 80 & $\begin{array}{l}\text { Partially } \\
\text { sighted } \\
\text { (Retinitis } \\
\text { Pigmentosa) }\end{array}$ & $\begin{array}{lr}\text { Doro } & \text { phone, } \\
\text { talking } & \text { book, } \\
\text { desktop } & \text { magnifier }\end{array}$ & $\begin{array}{l}\text { Interview and } \\
\text { observation at home } \\
(2 \mathrm{hr})\end{array}$ \\
\hline P10 & $\mathrm{W}$ & 70 & $\begin{array}{l}\text { Partially } \\
\text { sighted }\end{array}$ & $\begin{array}{l}\text { iPhone, MacBook, } \\
\text { Amazon Fire } \\
\text { tablets, Kindle, } \\
\text { Amazon Echo }\end{array}$ & $\begin{array}{l}\text { Interview and } \\
\text { observation at home } \\
(2 \mathrm{hr})\end{array}$ \\
\hline P11 & $\mathrm{W}$ & 35 & $\begin{array}{l}\text { Partially } \\
\text { sighted } \\
\text { (Retinitis } \\
\text { Pigmentosa) }\end{array}$ & $\begin{array}{l}\text { iPhone, wireless } \\
\text { keyboard, Braille } \\
\text { typewriter }\end{array}$ & $\begin{array}{l}\text { Interview and } \\
\text { observation at home } \\
(2 \mathrm{hr})\end{array}$ \\
\hline
\end{tabular}

Table 1. Participants details and devices used. 
Observations ranged from mobile, laptop and assistive technology use to home appliance use and brief home tours. Three participants were observed in-situ during their shift at the reception desk of the charity where contextual interviews were conducted, and were asked to explain and describe the tasks they normally carry out. Mostly, demonstrations were carried out at home while more 'naturalistic' observations took place at work. We aimed to let participants' activities drive our investigation, occasioning explanations by them, including how, when, and how often they perform them. Participant accounts were collected using a mix of fieldnotes, photos, audio and video recordings and video for interviews and observations.

\section{Data analysis}

Data gathered in fieldwork was assembled in an ethnographic record [12] consisting of participants' mundane practices conducted in their everyday lives (note we use the term 'mundane' to emphasise that such practices are thoroughly 'unremarkable' to participants). Most of these practices involved mainstream and assistive technologies to different extents, but there were also a few accounts of practices where technology is not present. Drawing on an ethnomethodological orientation, we present examples of how different key practices are accomplished, displaying exhibits of different competencies in turn.

\section{EVERYDAY PRACTICES OF VISUALLY IMPAIRED PEOPLE INVOLVING TECHNOLOGY}

Devices and tools used by participants are summarised in Table 1. Before we go into further depth, we wish to paint a broad picture of participants' engagements with technology.

Mobile phones were mentioned as essential for everyday activities by all except P4 and P9 (93 and 80 years old respectively), who own Doro phones (accessible mobile phones that have a physical keyboard). P8 also owns a Doro phone. Participants using iPhone and Samsung smartphones reported using the corresponding screen reader (i.e. VoiceOver, TalkBack) and voice assistant (i.e. Siri, Google Assistant). For five participants, these features were indispensable to operate their phones, whilst the rest enable the screen reader intermittently and use the voice assistant at their convenience. Laptop and desktop computers are mostly used by participants with low vision and a few who are blind, but only for specific purposes (e.g. online shopping), although accessibility issues are frequently encountered.

Furthermore, eight participants reported using mobile voice assistants for what they defined as 'simple tasks': asking the time, date and battery level; consulting weather forecasts; making calls; composing text messages and emails; playing music; quick and short online queries; opening apps; and enabling/disabling device features such as screen readers. Five participants reported using these many times a day. The married couple (P7, P10) are active users of three Amazon Echo devices at home.
Across the practices of all eleven participants, three main sites of practice were identified that feature the use of mainstream and assistive technologies that we unpack further in the following: social relations and communication practices, textual reading practices, and mobility practices. People use different devices, tools, features, and software, based on their individual competencies and preferences, and employ different methods for achieving these tasks.

\section{Social relations and communication practices}

We start with the most critical of activities, which obviously revolve around social relations. As a daily activity, most participants reported encountering little to no challenges. Quite prosaically we found that, for our participants, phones and computers act as crucial facilitators of social relations and communications practices with family, carers, friends and organisations (e.g. hospital, bank). All participants had developed proficient methods for making calls, sending text messages or emails, and reading received messages. Herein we describe, and present exhibits of, how communication and socialising activities arise through the use of assistive and mainstream technologies.

The communication activities of P4 and P9 consisted of making calls using landline telephone and the accessible mobile phone. These devices have been acquired specifically to address participants' low vision; thus, they have physical keyboards and large sized numbers. P4 and P9 have also roughly learned the keyboard/button arrangement of these devices and through tactile interactions, they can adequately operate them despite their sight loss.

For smartphone users, making calls and sending text messages and emails is done through voice assistants, screen readers or the graphic interface. Different methods and combinations of mediums are employed by participants based on personal preferences, conditions and specific situations. We present three examples of different types of interaction in which participants demonstrated (to the ethnographer) smartphone practices that allow them to communicate with others in their everyday lives.

\section{Fragment 1. Using Siri for text messaging}

P1 holds down the home button on his iPhone and right after, utters the command:

P1: Message A.H.

Siri: [beep] What do you want to say? [beep]

P1: [moves phone closer to his face] (Fig. 1a) Hello [brief pause] how are you? [moves phone away from his face] [waits].

Siri: [beep] Here's your message. Ready to send it? [beep].

P1: Yes.

Siri: [beep] OK, it's sent [beep].

P1: So, I've just messaged a friend in another room. And now he would've received that message. It saves me going into my phone. If I'm out and about in public, again it's a confidence thing; I don't really like having to hold my phone right to my face [moves phone to demonstrate] (Fig. 1b). So, when I have my headphones in, I can just make a basic Siri command to send a message. It's the same with a phone call. 


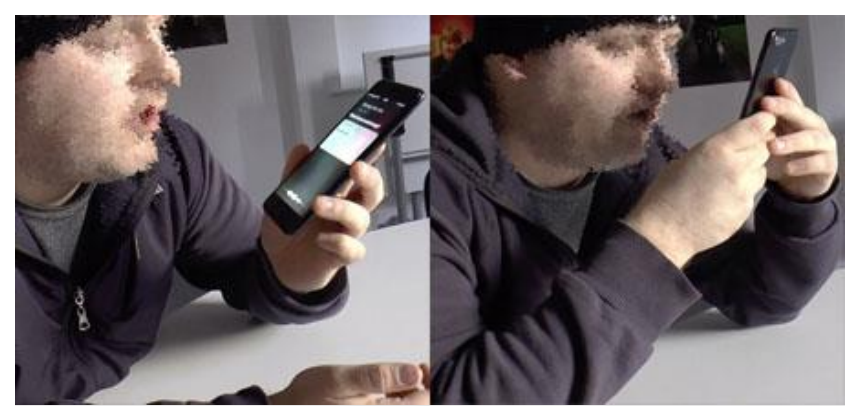

Figure 1. a) P1 using Siri (left) and b) demonstrating interaction he avoids in public (right).

Additionally, P1 pointed out the difference of using Siri when VoiceOver is enabled.

Siri: [beep] What do you want to say? [beep].

P1: Good afternoon [brief pause] how are you? [waits].

Siri: [beep] Your message to G says good afternoon how are you. Ready to send it? [beep].

P1: Yes.

P1: The thing is... when you do send a message with VoiceOver on, it will read back the message you've just said... So, I know what's been said or if there's been like, any grammatical mistakes.

In this fragment we note that although $\mathrm{P} 1$ is partially sighted and can see the screen's visual interface, he needs to put the screen very close to his face in order to do so (Fig 1b) and therefore prefers to use Siri. P1 provides multiple accounts for his preference here: improved "confidence" but also convenience ("it saves me going into my phone") when he is in public. So, in P1's account, voice assistant capabilities are to be mastered so as to provide for social acceptability by others (we note the imposition of particular normative behaviours often experienced by those with disabilities). This is in tension with the enhanced flexibility of interaction that voice assistants provide. It is also important to note, the way in which P1 articulates his message, by employing brief pauses that might indicate a comma or period, however, these are not captured as such by the assistant. Moreover, as he frequently uses Siri with and without VoiceOver enabled, he recognises the differences between such modalities, in which the latter allows him to revise the message before sending it, by listening to it instead of looking at the screen.

Fragment 2. Using screen reader to compose text message Conversely, P5's preferred modality for composing text messages is through the messaging app, using the keyboard with VoiceOver enabled. In this fragment, we include a short but noteworthy event that occurred at the beginning of this demonstration, as P5 adjusted the speech rate of the screen reader. The following sets of interactions were produced in the span of 4 seconds:

1. P5 taps with two fingers (right index and right middle) in the middle of the screen to stop the output from screen reader.

2. P5 taps with left thumb in the middle of the screen while swiping down with right index, starting from the top of the screen and releasing at the bottom. (Fig. 2)

3. P5 taps with two fingers (right index and right middle) in the middle of the screen to stop the output from screen reader.
4. P5 repeats interaction 2, two more times until "Speaking rate" is heard.

5. P5 swipes down with right index, starting from the middle of the screen and releasing before getting to the bottom. (Fig. 2)

After reaching $60 \%$, P5 stopped and indicated: "I just put the speed down, so you can hear as well". Then, she proceeded to continue the demonstration. She located the Messaging app at the top left corner in the home screen, opened it by double tapping and scrolled through her conversations. As VoiceOver read aloud the contact name and the latest message for each conversation, P5 tapped with two fingers to stop the screen reader after she heard the contact name. By double tapping a selected conversation, she proceeded to write the text message.

P5: So, now I've opened the text and what I'm gonna do is to find the compose box [taps on the bottom of the screen] (Fig. 3a).

VoiceOver: Message, text message.

P5: [taps on the bottom of the screen and slides finger over keyboard] (Fig. 3b).

VoiceOver: Space, Delete, Return.

P5: [taps with two fingers to stop Voice Over] So, now I'm on the box where I can, I got keyboards open so I can type in. So whatever letter I put my finger on, it will read out the letters...

[P5 types the message.]

P5: So, once I've typed the message, I find the text box [scrolls up] VoiceOver: Text field.

P5: And then scroll to the right with one finger [scrolls right].

VoiceOver: Send button.

P5: And then I just double tap to send it. [double taps].

This fragment displays P5's preferred practice to communicate with others via text message, which is accomplished through VoiceOver. As a screen reader expert user, P5 has set the speech rate with which the screen reader narrates the content to a fast pace [9]. Initially P5 performed a series of combined gestures to decrease the speech rate for the researcher. Not only the gestures were complex, but they were also performed in a very short time, demonstrating proficient use. Moreover, P5 continuously used the shortcut to stop the screen reader output (i.e. two fingers in the middle of the screen), which allowed her to continue with the demonstration. Lastly, we note the method she uses to locate elements on the screen (Fig 3) that allows her to conduct the task.

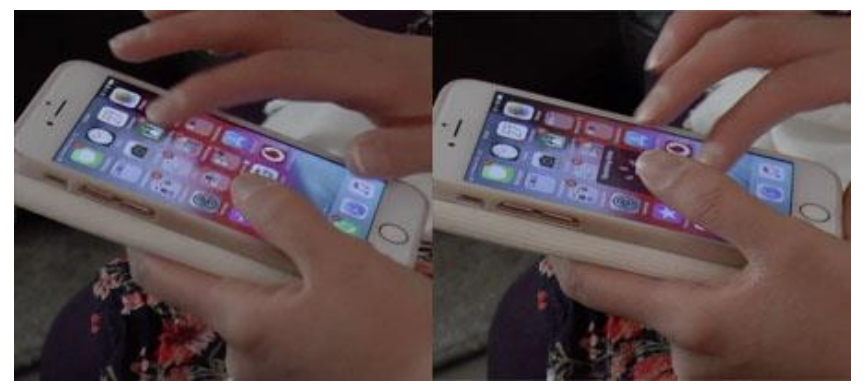

Figure 2. Performing gestures with both hands: tapping with left thumb and swiping with right index. 


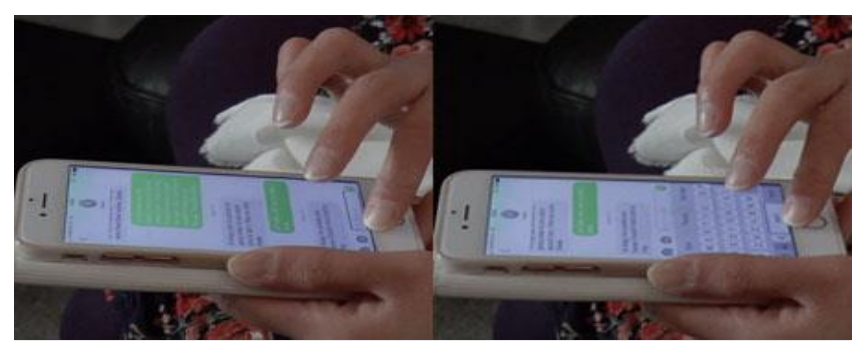

Figure 3. a) Locating text box (left) and b) keyboard (right) on the screen.

P5 displayed knowledge of the screen layout (e.g. compose box at the bottom, send button to the right of the text box) and then she explored the screen in order to find other elements (e.g. keyboards). Overall, the fragment demonstrates the relationship between P5's blindness and her proficient competency that combines complex gestural 'muscle memory' with auditory skills.

Fragment 3. Using dictation for text messaging

In contrast, P6 showed yet another modality through which he prefers to send text messages. By employing the dark screen mode and large font (accessibility features) he opened the Messages app and scrolled through his conversations, then selected a contact and instead of typing the message, he held down the microphone icon and dictated it.

P6: It's so much simpler, even that little message would take me three times as long, trying to find the keys and everything, so that it's really helpful... especially outside if there's a bright sunny day, I've got no chance of finding the keys. To be able to actually speak the text is marvellous.

In this fragment we see again that preference of modality is linked to convenience but also indicates that such practices develop in deep relationship to the particular character of visual impairment. P6 uses a combination of accessibility features that allow him to find and app and a contact/conversation by using his sight, but then chooses not to type on the keyboard. Furthermore P6 points out being additionally impaired by the environment $[2,46]$, which makes the dictation option, his best chance to accomplish the practice to text others.

We note a contrast between participants here that is interesting. P1, who is partially sighted, prefers to use voice interaction, while $\mathrm{P} 5$, who is blind, prefers to engage with the keyboard through the screen reader. Participants reported feeling confident about these practices and displayed concrete competencies developed in the course of performing them on a frequent manner. The competencies observed in this section include engaging with tactile, spatial (on screen) and auditory interactions. The first fragment also gives a glimpse of the need for competent articulation of commands to mobile voice assistants. Lastly, they showed different configurations on participants' devices, by setting up shortcuts (e.g. stopping VoiceOver) and feature preferences (e.g. speech rate).

\section{Textual reading practices}

The prevalence of textual information in the world is one of the core challenges that recurrently emerged from our study. While these activities tend to be supported by a range of established and mature forms of assistive technologies, the route to self-determination and the development of competence is hindered in various ways. Once again, participants needed to develop competencies in the form of sets of practices based around 'reading'; practices that worked with the nature of their particular VI. This posed far more challenges, however, than just that of managing social relationships and communication practices.

Again, screen readers on mobile phones were pointed out as essential to read digital and online content, for both blind and partially sighted people. Three participants reported reading Braille and two type it on manual and electronic devices. Most of the participants reported accessing books through a range of devices (e.g. smart speakers, electronic readers) and resources (e.g. audiobooks, e-books). However, reading information in the physical world still proves to be one of the most challenging activities in their day-to-day lives, no matter their sight condition. Participants reported struggling to read documents received by mail (e.g. statements, letters, leaflets), handwriting, street signs, food menus and labels on products (e.g. food, toiletries). Regarding the latter, participants expressed they wished to know specific details about these product (e.g. ingredients, presentation, colours), not just identification. Moreover, participants reported struggling to read information on digital screens: P6 had to stop working in a supermarket after several years when they introduced touch screens; and four participants pointed out complications in reading text on home appliances (e.g. digital displays). Here technology introduces retrograde steps that break established competencies.

The primary practice employed by participants for accessing information is recruiting assistance from others. Although partially sighted participants described and showed various types of visual aids for low vision (desktop and portable magnifiers); they also reported preference for the former in public settings (e.g. restaurants, shops) for saving time and avoiding prejudice from strangers (in a sense, similar to P1's account of why he used Siri). For most participants, recruiting assistance takes place in the current location, but two participants also mentioned regular use of the app Be My Eyes, which provides remote help from sighted persons.

\section{Fragment 4. Using portable electronic magnifier}

While being at the reception desk during one observation session, P6 showed us his portable electronic magnifier which he normally carries in his backpack. The initiation of the study occasioned his reflection on his reading practices:

P6: If I had got the time to go through the consent form that we'd just filled in, I could've probably done it eventually, but it would've took me a considerable amount of time. I can increase it or decrease it (font size). I prefer white writing on 
a black background... You can also bring it up really large, but the only trouble with that is that it takes a bit of time.

In this fragment, P6 refers to the informed consent procedure he'd just gone through for taking part in the research. The information was available to participants in different modalities (e.g. digital, paper) so they could choose their preferred one. P6, as the majority of participants, chose to have the information read aloud by the researcher. P6 acknowledged he is able to read the document using the magnifier; however, he chose not to for saving time. Similarly, other participants expressed preference for requesting assistance when reading product labels while shopping. P1 said "like reading labels in the supermarket, I'd get a friend to, I'd just use their eyes if that makes sense", and $\mathrm{P} 9$ indicated "I'm very good at asking for help, you just have to be honest. When I go out now, if I'm on my own I've always got a white stick, so people recognise the problem".

Practices with assistive devices require a level of proficiency, such as learning magnifier controls and developing the habit of carrying such portable devices with them when potentially needed. These practices also illustrate tactile (e.g. pressing buttons) and spatial competencies (e.g. positioning and moving magnifier over document).

Lastly, one of the core reading practices adopted by eight participants is the use of scanning and optical character recognition (OCR) mobile apps. Five participants use Seeing $\mathrm{AI}$ and three participants use KNFB reader; they all indicated using them on a daily basis. Both apps work broadly in a similar way: the user takes a picture of the document or text, the phone processes the picture, and reads the text aloud. In the following, P2 shows two ways of using the OCR app.

\section{Fragment 5. Using Seeing Al to read tin label}

P2 has installed a set of "Velcro stations" around his house (e.g. on the side of the fridge, next to his bed). The other end of the Velcro is on the back of his iPhone, so he can place and temporarily attach his phone to such stations, allowing him to know the exact location of the device. In a similar way, he has installed a metal shelf on the side of the fridge which helps him to scan objects using his mobile.

P2: I attached that [points metal shelf] to the fridge [places mobile on the shelf, the app is ready to scan] because trying to scan objects is annoying sometimes, trying to get the right range... So, let's look at the thin [takes a tin out of cupboard]. Hopefully... you'd probably call me a liar now [puts down the tin, horizontally, and slides it towards the fridge] I should be able to- [tin hits fridge surface, he starts to slightly slide and turn the tin] (Fig. 4a).

Mobile: [beeps shortly and flashes].

P2: Oh, that [releases the tin].

Mobile: Processing. [short pause] Ambrossia cream rice sultanas [unintelligible words].

P2: You see how quick that was? Whereas if you take it off the shelf [takes phone], trying to do it like this [holds phone with right hand in front of tin] the same action [uses left hand to direct tin to mobile and then releases tin] (Fig. 4b).

Mobile: [beeps intermittently].

P2: You see how long it takes? [slightly moves phone].

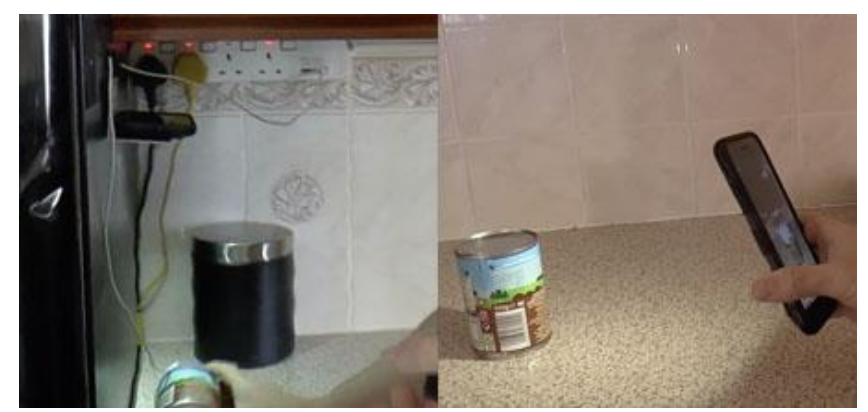

Figure 4. Using Seeing AI to read a tin label: a) with phone attached to a shelf (left) and b) holding phone with hand (right).

Mobile: [stops beeping].

P2: [Continues moving phone to the sides] I've completely lost...

Mobile: [beeps intermittently].

P2: [Stops moving mobile].

After ten seconds of sliding the mobile to the sides, closer and farther from the tin, a picture was taken.

P2: See the difference between putting it on there [points shelf] and put it like that [points the tin on the counter]. The time taken is ridiculous.

This fragment illustrates in first instance, the configuration work of P2 as he has installed "Velcro stations" across his house. Furthermore, it demonstrates two different ways in which he renders the elements in the world. He has found that scanning an object by holding the phone with a hand, as a sighted person would do (Fig 4b), poses alignment challenges that he cannot easily repair. In consequence, he has adapted the space (installed a shelf) and modality of use of the app in order to make the process easier and straightforward for him. Once again, the time taken to achieve the task is reported as relevant, as the first method was very smooth and quick, whereas the second method took over ten seconds and provided more uncertainty. The second method, however, shows $\mathrm{P} 2$ discerning auditory feedback, or the lack thereof, from the app, which indicates him to move or hold the phone still. The need for precision of OCR apps requires good spatial and auditory competencies, or as shown by this fragment, adaptation and configuration work.

Overall, technological solutions have been developed to allow people with visual impairments to access printed information. However, seamlessness or fluidity in such experiences are not the norm. Thus, requesting assistance to others remains the most reliable, and in some cases the quickest practice for reading text in the world.

\section{Mobility practices}

Mobility also poses significant challenges for people with VI, especially those who are blind or severely impaired. These practices are closely interrelated with text messaging (see Frag. 1 and 3), and textual reading (see Frag. 4), especially in public settings. Participants presented different levels of mobility independence based on their eye and motor condition, personal confidence and familiarity with the environment. In this section we describe a few practices that enable different types of mobility in the participants' lives, with and without technology support. 
Participants observed at home expressed comfort and safety in their private space. Naturally, home spaces tended to be subject to considerable configuration work by participants to establish them as sites that worked for their particular impairments (see Frag. 5). Inside their own spaces, participants demonstrated significant competencies in spatial awareness, not needing canes or other assistance to move around. However, they struggle to identify objects. To cope with this, participants rely on tactile interactions, although two of them indicated their fingertips are not as sensitive and some surfaces are hard to discern. Ten participants reported employing tactile or high contrast bands around objects (e.g. remote control), and a variety of adhesive or glued plastic bumps on switches, home appliances (e.g. microwave buttons) and touch screens (e.g. P7 has put adhesive dots on his mobile screen for guiding him when unlocking it). Similarly, P11 creates Braille labels and sticks them to personal products (e.g. makeup) so she knows what they are, their colour or material, or whatever she finds relevant. Placing bumps and creating labels usually requires colocated or remote assistant from others (e.g. exact location of bumps, product description), but thereafter participants can complete tasks on their own by using such markers.

Away from home, matters get complicated. Some participants mentioned visiting frequent places (e.g. shops, the charity) and feeling confident about their paths to get there and about such spaces. However, most participants expressed deliberately avoiding unfamiliar places or going out without company. In the following example P10 shares his personal experience on this matter.

Fragment 6. Partially sighted person taking the dog for a walk P10: When I take the dog out for a walk, I go the same route, because I trip over things, and as I get older, I find it more difficult. So, I go the same route every day. The dog I keep on the lead, I used to take him off the lead, but there's no way I can catch him if he runs off. I've got poo bags and I pick up after him, but I have to be literally behind him to see where he does it, cause if he does it a distance away from me, although I've got a rough idea where he's done it, when I get close to it, I can't see it. With such things like that, when I get from a distance, I can see what I've missed.

This fragment shows the reasoning behind P10's actions that are mostly based on her individual characteristics. Using the same route helps her to feel more confident when walking, and familiarity with it reduces the chances to experience tripping. We also observe that spatial awareness plays a crucial role in this practice, as it allows her to position herself, and her reduced sight, in relation to the open space and to the dog. This example shows how routines in outdoor mobility are highly relevant for people with VI.

Notably, regarding technological aids, all smartphone users from this sample choose not to use mobile applications tailored for outdoors use (e.g. wayfinding, object recognition) due to safety and privacy concerns (e.g. being exposed in public). Alternatively, four participants reported using taxi apps every week. This provides an intermediate level of independence, not having to navigate on their own outdoors, but allowing them to get to places without waiting for assistance. Four participants reported shopping on-site, all of them requesting help from shop clerks, family, friends or assistants (see Fragment 4). Conversely, six participants regularly shop online. Their preferred stores are selected mainly on the accessibility provided by their websites or mobile apps. Furthermore, five participants expressed positive comments of their banking apps, in which they can perform a set of tasks from their home (e.g. consulting balance, transferring money) and only P4 and P9 reported going to the bank regularly.

\section{DISCUSSION}

In this paper, we have outlined three main sites where technology is - and is not-involved in the everyday lives of people with VI: social relations and communication practices, textual reading practices, and mobility practices. From such participants' practices, we uncovered diverse competencies, articulated in various methods that recruit tools, particular motivations and individual preferences. Our findings also uncovered participants' configuration work of relations, environments and devices which allow them to accomplish their practices with little or no interference, or the least interference possible. This view does not preclude requesting assistance from others, but rather recognises participant's own methods (or 'ways') of 'getting on' in everyday life. By employing an ethnomethodological orientation, our findings highlight how participants' competencies comprise more than their visual condition.

\section{Ethnomethodology as a resource to study disability}

Critics of the social model of disability such as feminist approaches (e.g. [23,27]), have called for more holistic understandings of types of people who might be disabled, and centring their embodied experiences.

Our ethnomethodologically informed ethnographic approach [43] means we study the material organisation of everyday activities. In tipping our focus from disability-as-problem more towards unpacking practical action, we focussed on building descriptions of just how participants 'move on' in their everyday lives. But, we must underline that we are not arguing that research and design should neglect explanations of structural ableism in favour of situated local practices. Instead they act as complementary approaches to inform and shape one another.

This paper presents an overview of some of the practices that people with visual impairments construct themselves in order to do this. They are, naturally, related to mainstream and assistive technologies to varying extents. The findings presented here are broad in terms of scope, as the intention was not to delve in detail into specific domains, but rather to contribute holistic accounts of participants' lives, that could then demonstrate the various strategies they employ and how these are achieved. We recognise possible methodological concerns, as some data fragments captured were produced as 
demonstrations, which are phenomenologically different to capturing 'naturally occurring' activities ${ }^{1}$ [16,17,31]. However, it is important to note that demonstrations allowed our participants to give their personal account of the practices they were undertaking, highlighting elements that could pass unnoticed otherwise, given that they are, for participants, deeply unremarkable, and yet for the researcher, they are not. One of the concepts that ethnomethodology seeks to address, is the "taken-for-grantedness" [21] that results from being a competent member of a group. By the researcher not being a member of that group, and in and through their demonstrations, participants were prompted to reflect on such routine competencies that tend not to be developed by sighted persons, such as being able to comprehend synthesized speech at a very fast rate [9].

\section{How practices are enabled by competencies}

In this paper, we have unpacked different examples of the three sets of everyday practices observed in our research (social relations and communication, textual reading and mobility). Furthermore, we have uncovered different competencies that enable the accomplishment of those practices. Table 2 presents a summary of these key observations, some of which are discussed in the following.

The first three fragments presented how participants conduct their text messaging and highlight the diversity of methods employed by people with different visual impairments (e.g. voice assistant, screen reader, dictation tool). What we observe showcases a variety of competencies that participants develop, particular to the situated encounter. For instance, we see participants sending a text message by adapting to environment light conditions (e.g. see [2]) and by managing their (in)visibility in public (e.g. see [19]). Unexpectedly, we found that our low vision participants preferred not to engage with the graphic interface (see Frag. 1 and 3), something different from prior work [53,54]. They substitute it with the voice assistant or voice dictation, preferences that respond to the external factors encountered.

Textual reading practices pose more challenges for participants and they tended to discover more barriers to reading text found in the world. This could be due to the recipient design that is applied to the applications used for the latter, as communication requires two-way interaction by nature. We found that a primary practice to access printed information is requesting assistance. This is not something necessarily problematic [6,28]. Participants configure their relations and although they may employ visual aids, sometimes they prefer to ask for help, because that is what it feels more comfortable or convenient for them in that particular situation (see Frag. 4).

\footnotetext{
${ }^{1}$ We use terms like 'naturally occurring' yet note their problematic character-instead we use it here to underscore the phenomenological distinction we are making.
}

\begin{tabular}{|c|c|c|}
\hline Competency & Domain & Exemplars (Fragment) \\
\hline Auditory & $\begin{array}{l}\text { Sound recognition [57], } \\
\text { speech recognition [25], } \\
\text { speech rate [9]. }\end{array}$ & $\begin{array}{l}\text { Detecting cues from apps (F1, } \\
\text { F5), listening to screen reader } \\
(\mathrm{F} 2, \mathrm{~F} 5) \text { at a fast rate }(\mathrm{F} 2)\end{array}$ \\
\hline Spatial & $\begin{array}{l}\text { Space awareness } \\
\text { [36,52], object } \\
\text { orientation and } \\
\text { positioning [58]. }\end{array}$ & $\begin{array}{l}\text { Scanning tin label with OCR } \\
\text { app (F5), reading document } \\
\text { with portable magnifier (F4) }\end{array}$ \\
\hline Tactile & \begin{tabular}{|l|} 
Surface exploration \\
{$[52,65]$, gestures $[51]$.}
\end{tabular} & $\begin{array}{l}\text { Exploring touchscreen (F2), } \\
\text { locating physical buttons (F4), } \\
\text { finding objects on shelf (F5), } \\
\text { modifying mobile settings } \\
\text { through gestures (F2), }\end{array}$ \\
\hline Verbal & $\begin{array}{l}\text { Speech input (command } \\
\text { articulation, dictation) } \\
\text { [4]. }\end{array}$ & Texting via voice $(\mathrm{F} 1, \mathrm{~F} 3)$ \\
\hline Cognitive & $\begin{array}{l}\text { Information and } \\
\text { experience recall [45]. }\end{array}$ & $\begin{array}{l}\text { Recalling location of visual } \\
\text { elements on screen (F2), } \\
\text { recalling walking route (F6) }\end{array}$ \\
\hline Social & $\begin{array}{l}\text { Requesting assistance } \\
\text { (co-located or remote) } \\
{[6,28], \text { visibility in }} \\
\text { public [19]. }\end{array}$ & $\begin{array}{l}\text { Asking someone to read a } \\
\text { document aloud (F4), } \\
\text { Blending in public (F1) }\end{array}$ \\
\hline Adaptation & $\begin{array}{l}\text { Routines }[16,17] \text {, } \\
\text { environment conditions } \\
{[2] .}\end{array}$ & $\begin{array}{l}\text { Carrying portable magnifier } \\
\text { (F4), walking the dog on the } \\
\text { same route (F6), dictating } \\
\text { message outdoors (F3) }\end{array}$ \\
\hline Configuration & $\begin{array}{l}\text { Digital (shortcuts, } \\
\text { features) [30,60], } \\
\text { physical (space, tools) } \\
\text { [7]. }\end{array}$ & $\begin{array}{l}\text { Using shortcuts on mobile } \\
\text { (F2), setting dark screen mode } \\
\text { (F3, F4), installing mobile } \\
\text { stations at home (F5) }\end{array}$ \\
\hline
\end{tabular}

Table 2. Participants' sets of competencies.

Furthermore, participants have developed a range of competencies to access printed information on their own, that are demonstrated by the use of various devices and resources. We suggest that competencies are also displayed in the form of space adaptation and configuration work, when the competencies required to use a device are not fulfilled. For example, P2's practices for scanning with an OCR app the information on a tin label in two modalities. The first was enabled by configurating space and tools in the form of Velcro stations for attaching the phone to a fixed position and the second by positioning, orienting and moving phone and tin for successful alignment. The latter was also enabled by detecting the app audio feedback that indicated what to do. Both modalities were also enabled by kitchen surfaces and objects exploration (i.e. counter, shelves, tin). We also want to point out the examples in which technology breaks existing established developed competencies (i.e. touch screens and digital displays), and how this problem may arise from the lack of articulation of present competencies in design. Lastly, we found that a decisive criterion defining participants' preferences is the time taken to complete a task. Some assistive technologies 
may be effective but not efficient, which in the case of the visually impaired represents longer times to do simple tasks.

Mobility practices also pose challenges to our participants, and technologies are embedded indirectly in the form of services that allow them to accomplish activities without navigating entirely on their own (e.g. see [28]). They also indicated avoiding navigation aids in public because they are not trustworthy or precise enough, and for privacy and safety reasons. Mobility in known spaces is largely enabled by configuration work, while mobility in public settings is mostly facilitated by recalling and using the same routes (see Frag. 6). Naturally, mobility is enabled by spatial awareness for positioning in reference to the space and to other entities or subjects. A recurrent concern stated by participants across all practices, but especially those who involved public spaces or being in presence of strangers, was to feel exposed as visually impaired. Unpacking methods in these cases can produce descriptions of how participants navigated structural ableism. Some employ methods to keep a low profile in public (see Frag. 1) and others disclose their VI upfront when requesting assistance.

\section{Reframing disability as competency}

It is a common belief that the absence of a sense produces further development of other senses (e.g. blind people heavily rely on their hearing sense). More specifically, within AT research, there has been a longstanding argument for using the special skills of "extra-ordinary" people [35] in mainstream technology design. Nevertheless, we see a gap in research that is centred upon investigating and documenting such special skills. When emphasis resides on locating barriers and developing technological solutions to remove them, there is a risk to overlook people's current practices (and therefore competencies). While past research has further investigated social and material workarounds providing noteworthy accounts of them [7,10,30,48,49,55], we aimed to contribute to this body of knowledge by delivering more explicit and detailed instances, not often found in HCI research. Furthermore, our main contribution lies in our stance to recognise and uncover competency in disability by centring our emphasis on 'what people can do' - a core component of the ability-based design framework [63] — which has been an influential baseline for considerable AT research. Nevertheless, we see that projects using this framework or similar tend to measure ability in terms of performance, accuracy and speed [40,63]. While such a tendency is highly valuable for improving interaction techniques and automatically adapting systems to users' functional abilities, it does not comprise other individual (e.g. personal attitudes) and external elements (e.g. social situation) that also play an important role in the adoption and use of AT [50]. In this research we provide a complementary approach to current frameworks and paradigms in the field, that could help to obtain richer understandings of how people live with visual impairments.
Naturally, previous work has addressed and/or engaged with the competencies unearthed in our study to different extents (see references in Table 2), for investigating how they arise or to design and evaluate prototypes that make use of them. However, to the best of our knowledge, the few attempts to characterise and construct the spectrum of human abilities only comprise sensory and cognitive layers [40]. We have not seen the articulation of people's abilities and the methods employed in their everyday lives, in terms of competencies. Moreover, the competencies we have ascertained, emerged from study data rather than theoretical models. Our findings also align with recent calls to consider AT embeddedness in society $[6,28,50]$, and thus, we present an understanding of competency in disability that comprises sensory, cognitive, social and individual layers. Determining abilities in this way can help to extend or support people's current abilities (competencies) rather than substituting or obstructing them through the use and development of technological aids [55]. We suggest awareness of these competencies could be used by designers and researchers as another starting point for future work that explores how they are comprised, obtained, and/or developed and how they could be supported, in contrast to research that emphasizes locating accessibility challenges in order to build or improve technology that removes them. Future steps emerging from this research must also include direct engagement with target users to validate and further develop this competency approach to investigate, and design for, visual impairments.

\section{CONCLUSION}

A four-month ethnographic study was carried out at a charity that supports people with visual impairments. Through interviews, researcher observation and fieldwork we uncovered three main sites arising from participants' practices where technology is embedded to different extents: social relations and communication, textual reading, and mobility. By employing an ethnomethodological approach we unpacked such practices and unearthed the competencies that enable their accomplishment. These were presented and further classified as auditory, spatial, tactile, verbal, cognitive, social, adaptation and configuration work. We argue that looking with detail into the various strategies that people with visual impairments- and other disabilities-carry out to 'get by', can contribute to a better understanding of 'what people can do'; and furthermore, that developing an awareness of their competencies, can enrich design of assistive and mainstream technologies.

\section{ACKNOWLEDGEMENTS}

This work is supported by the National Council of Science and Technology of Mexico (CONACYT). This work is supported by the Engineering and Physical Sciences Research Council [grant numbers EP/N014243/1, EP/M02315X/1]. We are grateful for the support of staff, volunteers, and service users of MySight, Nottingham, UK.

\section{REFERENCES}

1. Ali Abdolrahmani, Ravi Kuber, and Stacy M. Branham. 2018. "Siri Talks at You”: An Empirical 
Investigation of Voice-Activated Personal Assistant (VAPA) Usage by Individuals Who Are Blind. Proceedings of the 20th International ACM SIGACCESS Conference on Computers and Accessibility - ASSETS '18, ACM Press, 249-258.

2. Ali Abdolrahmani, Ravi Kuber, and Amy Hurst. 2016. An empirical investigation of the situationally-induced impairments experienced by blind mobile device users. Proceedings of the 13th Web for All Conference on W4A '16, ACM Press, 1-8.

3. Mauro Avila, Katrin Wolf, Anke Brock, and Niels Henze. 2016. Remote Assistance for Blind Users in Daily Life: A Survey about Be My Eyes. Proceedings of the 9th ACM International Conference on PErvasive Technologies Related to Assistive Environments PETRA '16, ACM Press, 1-2.

4. Shiri Azenkot and Nicole B. Lee. 2013. Exploring the use of speech input by blind people on mobile devices. Proceedings of the 15th International ACM SIGACCESS Conference on Computers and Accessibility - ASSETS '13, ACM Press, 1-8.

5. Rachel Bartlett, Yi Xuan Khoo, Juan Pablo Hourcade, and Kyle K. Rector. 2019. Exploring the Opportunities for Technologies to Enhance Quality of Life with People who have Experienced Vision Loss. Proceedings of the 2019 CHI Conference on Human Factors in Computing Systems - CHI '19, ACM Press, $1-8$.

6. Cynthia L. Bennett, Erin Brady, and Stacy M. Branham. 2018. Interdependence as a Frame for Assistive Technology Research and Design. Proceedings of the 20th International ACM SIGACCESS Conference on Computers and Accessibility - ASSETS '18, ACM Press, 161-173.

7. Cynthia L. Bennett, Burren Peil, and Daniela K. Rosner. 2019. Biographical Prototypes: Reimagining Recognition and Disability in Design. Proceedings of the 2019 on Designing Interactive Systems Conference - DIS '19, ACM Press, 35-47.

8. Alexy Bhowmick and Shyamanta M. Hazarika. 2017. An insight into assistive technology for the visually impaired and blind people: state-of-the-art and future trends. Journal on Multimodal User Interfaces 11, 2: 149-172.

9. Danielle Bragg, Cynthia Bennett, Katharina Reinecke, and Richard Ladner. 2018. A Large Inclusive Study of Human Listening Rates. Proceedings of the 2018 CHI Conference on Human Factors in Computing Systems - CHI '18, ACM Press, 1-12.

10. Stacy M. Branham and Shaun K. Kane. 2015. Collaborative Accessibility: How Blind and Sighted Companions Co-Create Accessible Home Spaces.
Proceedings of the 33rd Annual ACM Conference on Human Factors in Computing Systems - CHI '15, ACM Press, 2373-2382.

11. Michele A Burton, Erin Brady, Robin Brewer, Callie Neylan, Jeffrey P Bigham, and Amy Hurst. Crowdsourcing subjective fashion advice using VizWiz: challenges and opportunities. 8.

12. Andrew Crabtree, Mark Rouncefield, and Peter Tolmie. 2012. Doing design ethnography. Springer.

13. Michael D. Crossland, Rui S. Silva, and Antonio F. Macedo. 2014. Smartphone, tablet computer and ereader use by people with vision impairment. Ophthalmic and Physiological Optics 34, 5: 552-557.

14. Rafael Jeferson Pezzuto Damaceno, Juliana Cristina Braga, and Jesús Pascual Mena-Chalco. 2018. Mobile device accessibility for the visually impaired: problems mapping and recommendations. Universal Access in the Information Society 17, 2: 421-435.

15. Guy Dewsbury *, Karen Clarke, Dave Randall, Mark Rouncefield, and Ian Sommerville. 2004. The antisocial model of disability. Disability \& Society 19, 2: 145-158.

16. Brian L Due and Simon Bierring Lange. 2018. Troublesome Objects: Unpacking Ocular-Centrism in Urban Environments by Studying Blind Navigation Using Video Ethnography and Ethnomethodology. Sociological Research Online: 136078041881196.

17. Brian Due and Simon Lange. 2018. Semiotic resources for navigation: A video ethnographic study of blind people's uses of the white cane and a guide dog for navigating in urban areas. Semiotica 2018, 222: 287312.

18. Silvia B. Fajardo-Flores, Laura S. Gaytán-Lugo, Pedro C. Santana-Mancilla, and Miguel A. Rodríguez-Ortiz. 2017. Mobile Accessibility for People with Combined Visual and Motor Impairment: A case Study. Proceedings of the 8th Latin American Conference on Human-Computer Interaction - CLIHC '17, ACM Press, 1-4.

19. Heather A. Faucett, Kate E. Ringland, Amanda L. L. Cullen, and Gillian R. Hayes. 2017. (In)Visibility in Disability and Assistive Technology. ACM Transactions on Accessible Computing 10, 4: 1-17.

20. Christopher Frauenberger. 2015. Disability and Technology: A Critical Realist Perspective. Proceedings of the 17th International ACM SIGACCESS Conference on Computers \& Accessibility - ASSETS '15, ACM Press, 89-96.

21. Harold Garfinkel. 1967. Studies in ethnomethodology.

22. Harold Garfinkel and Anne Warfield Rawls. 2002. Ethnomethodology's program: working out Durkeim's 
aphorism. Rowman \& Littlefield Publishers, Lanham, Md.

23. Rosemarie Garland-Thomson. 2005. Feminist Disability Studies. Signs: Journal of Women in Culture and Society 30, 2: 1557-1587.

24. João Guerreiro, Dragan Ahmetovic, Daisuke Sato, Kris Kitani, and Chieko Asakawa. 2019. Airport Accessibility and Navigation Assistance for People with Visual Impairments. Proceedings of the 2019 CHI Conference on Human Factors in Computing Systems - CHI '19, ACM Press, 1-14.

25. João Guerreiro and Daniel Gonçalves. 2014. Text-tospeeches: evaluating the perception of concurrent speech by blind people. Proceedings of the 16th international ACM SIGACCESS conference on Computers \& accessibility - ASSETS '14, ACM Press, 169-176.

26. Tiago Guerreiro, Joaquim Jorge, and Daniel Gonçalves. 2010. Identifying the relevant individual attributes for a successful non-visual mobile experience. Proceedings of the 28th Annual European Conference on Cognitive Ergonomics - ECCE '10, ACM Press, 27.

27. Alison Kafer. 2013. Feminist, queer, crip. Indiana University Press, Bloomington, Indiana.

28. Vaishnav Kameswaran, Jatin Gupta, Joyojeet Pal, et al. 2018. "We can go anywhere": Understanding Independence through a Case Study of Ride-hailing Use by People with Visual Impairments in metropolitan India. Proceedings of the ACM on Human-Computer Interaction 2, CSCW: 1-24.

29. Shaun K. Kane, Jeffrey P. Bigham, and Jacob O. Wobbrock. 2008. Slide rule: making mobile touch screens accessible to blind people using multi-touch interaction techniques. Proceedings of the 10th international ACM SIGACCESS conference on Computers and accessibility - Assets '08, ACM Press, 73.

30. Shaun K. Kane, Chandrika Jayant, Jacob O. Wobbrock, and Richard E. Ladner. 2009. Freedom to roam: a study of mobile device adoption and accessibility for people with visual and motor disabilities. Proceeding of the eleventh international ACM SIGACCESS conference on Computers and accessibility - ASSETS '09, ACM Press, 115.

31. Dirk vom Lehn. 2010. Discovering 'Experience-ables': Socially including visually impaired people in art museums. Journal of Marketing Management 26, 7-8: 749-769.

32. Barbara Leporini, Maria Claudia Buzzi, and Marina Buzzi. Interacting with mobile devices via VoiceOver: usability and accessibility issues. 10 .
33. Julie Miller, Samantha Brady, Chaiwoo Lee, et al. 2018. How The "Oldest Old" Experience and Adapt to Vision and Hearing Loss Through the Use of Assistive Technologies. Proceedings of the Technology, Mind, and Society on ZZZ - TechMindSociety '18, ACM Press, 1-5.

34. Meredith Ringel Morris, Annuska Zolyomi, Catherine Yao, Sina Bahram, Jeffrey P. Bigham, and Shaun K. Kane. 2016. "With most of it being pictures now, I rarely use it": Understanding Twitter's Evolving Accessibility to Blind Users. Proceedings of the 2016 CHI Conference on Human Factors in Computing Systems - CHI '16, ACM Press, 5506-5516.

35. A. F. Newell and P. Gregor. 1999. Extra-Ordinary Human-Machine Interaction: What can be Learned from People with Disabilities? Cognition, Technology \& Work 1, 2: 78-85.

36. João Oliveira, Tiago Guerreiro, Hugo Nicolau, Joaquim Jorge, and Daniel Gonçalves. Blind people and mobile touch-based text-entry: acknowledging the need for different flavors. 8 .

37. Mike Oliver. 2013. The social model of disability: thirty years on. Disability \& Society 28, 7: 1024-1026.

38. World Health Organization. 2011. World report on disability 2011. World Health Organization.

39. Joyojeet Pal, Anandhi Viswanathan, Priyank Chandra, et al. 2017. Agency in Assistive Technology Adoption: Visual Impairment and Smartphone Use in Bangalore. Proceedings of the 2017 CHI Conference on Human Factors in Computing Systems - CHI '17, ACM Press, 5929-5940.

40. Umesh Persad, Patrick Langdon, and John Clarkson. 2007. Characterising user capabilities to support inclusive design evaluation. Universal Access in the Information Society 6, 2: 119-135.

41. Leah Lakshmi Piepzna-Samarasinha. 2018. Care work: Dreaming disability justice. arsenal pulp press.

42. Alisha Pradhan, Kanika Mehta, and Leah Findlater. 2018. "Accessibility Came by Accident": Use of Voice-Controlled Intelligent Personal Assistants by People with Disabilities. Proceedings of the $2018 \mathrm{CHI}$ Conference on Human Factors in Computing Systems - CHI '18, ACM Press, 1-13.

43. David Randall, Richard Harper, and Mark Rouncefield. 2007. Fieldwork for design: theory and practice. Springer Science \& Business Media.

44. André Rodrigues, Kyle Montague, Hugo Nicolau, and Tiago Guerreiro. 2015. Getting Smartphones to Talkback: Understanding the Smartphone Adoption Process of Blind Users. Proceedings of the 17th International ACM SIGACCESS Conference on 
Computers \& Accessibility - ASSETS '15, ACM Press, 23-32.

45. Jaime Sánchez and Héctor Flores. Memory Enhancement through Audio. 8.

46. Zhanna Sarsenbayeva, Vassilis Kostakos, and Jorge Goncalves. 2019. Situationally-Induced Impairments and Disabilities Research. 5.

47. Sami Schalk. 2018. Bodyminds Reimagined:(Dis) ability, Race, and Gender in Black Women's Speculative Fiction. Duke University Press.

48. Kristen Shinohara and Josh Tenenberg. 2007. Observing Sara: a case study of a blind person's interactions with technology. Proceedings of the 9th international ACM SIGACCESS conference on Computers and accessibility - Assets '07, ACM Press, 171.

49. Kristen Shinohara and Jacob O. Wobbrock. 2011. In the shadow of misperception: assistive technology use and social interactions. Proceedings of the 2011 annual conference on Human factors in computing systems CHI '11, ACM Press, 705.

50. Kristen Shinohara and Jacob O. Wobbrock. 2016. SelfConscious or Self-Confident? A Diary Study Conceptualizing the Social Accessibility of Assistive Technology. ACM Transactions on Accessible Computing 8, 2: 1-31.

51. Berglind F. Smaradottir, Jarle A. Håland, and Santiago G. Martinez. 2018. User Evaluation of the Smartphone Screen Reader VoiceOver with Visually Disabled Participants. Mobile Information Systems 2018: 1-9.

52. Ji-Won Song and Sung-Ho Yang. 2010. Touch your way: haptic sight for visually impaired people to walk with independence. Proceedings of the 28th of the international conference extended abstracts on Human factors in computing systems - CHI EA '10, ACM Press, 3343.

53. Sarit Felicia Anais Szpiro, Shafeka Hashash, Yuhang Zhao, and Shiri Azenkot. 2016. How People with Low Vision Access Computing Devices: Understanding Challenges and Opportunities. Proceedings of the 18th International ACM SIGACCESS Conference on Computers and Accessibility - ASSETS '16, ACM Press, 171-180.

54. Sarit Szpiro, Yuhang Zhao, and Shiri Azenkot. 2016. Finding a store, searching for a product: a study of daily challenges of low vision people. Proceedings of the 2016 ACM International Joint Conference on Pervasive and Ubiquitous Computing - UbiComp '16, ACM Press, 61-72.

55. Anja Thieme, Cynthia L. Bennett, Cecily Morrison, Edward Cutrell, and Alex S. Taylor. 2018. "I can do everything but see!" -- How People with Vision Impairments Negotiate their Abilities in Social Contexts. Proceedings of the 2018 CHI Conference on Human Factors in Computing Systems - CHI '18, ACM Press, 1-14.

56. Shannon M. Tomlinson. 2016. Perceptions of accessibility and usability by blind or visually impaired persons: A pilot study: Perceptions of Accessibility and Usability by Blind or Visually Impaired Persons: A Pilot Study. Proceedings of the Association for Information Science and Technology 53, 1: 1-4.

57. Shari Trewin, John Richards, Rachel Bellamy, et al. 2010. Toward modeling auditory information seeking strategies on the web. Proceedings of the 28th of the international conference extended abstracts on Human factors in computing systems - CHI EA '10, ACM Press, 3973.

58. Marynel Vázquez and Aaron Steinfeld. 2012. Helping visually impaired users properly aim a camera.

Proceedings of the 14th international ACM SIGACCESS conference on Computers and accessibility - ASSETS '12, ACM Press, 95.

59. Violeta Voykinska, Shiri Azenkot, Shaomei Wu, and Gilly Leshed. 2016. How Blind People Interact with Visual Content on Social Networking Services. Proceedings of the 19th ACM Conference on Computer-Supported Cooperative Work \& Social Computing - CSCW'16, ACM Press, 1582-1593.

60. Herman Wahidin, Jenny Waycott, and Steven Baker. 2018. The challenges in adopting assistive technologies in the workplace for people with visual impairments. Proceedings of the 30th Australian Conference on Computer-Human Interaction - $\mathrm{OzCHI}$ '18, ACM Press, 432-442.

61. Susan Wendell. 2013. The Rejected Body: Feminist Philosophical Reflections on Disability. Routledge.

62. Brian Wentz and Jonathan Lazar. 2011. Usability Evaluation of Email Applications by Blind Users. 6, 2: 15.

63. Jacob O. Wobbrock, Shaun K. Kane, Krzysztof Z. Gajos, Susumu Harada, and Jon Froehlich. 2011. Ability-Based Design: Concept, Principles and Examples. ACM Transactions on Accessible Computing 3, 3: 1-27.

64. Hanlu Ye, Meethu Malu, Uran Oh, and Leah Findlater. 2014. Current and future mobile and wearable device use by people with visual impairments. Proceedings of the 32nd annual ACM conference on Human factors in computing systems - CHI '14, ACM Press, 3123-3132.

65. Yuhang Zhao, Elizabeth Kupferstein, Doron Tal, and Shiri Azenkot. 2018. "It Looks Beautiful but Scary": How Low Vision People Navigate Stairs and Other 
Surface Level Changes. Proceedings of the 20th International ACM SIGACCESS Conference on Computers and Accessibility - ASSETS '18, ACM Press, 307-320.

66. Annuska Zolyomi, Anushree Shukla, and Jaime Snyder. 2017. Technology-Mediated Sight: A Case Study of Early Adopters of a Low Vision Assistive Technology. Proceedings of the 19th International ACM SIGACCESS Conference on Computers and Accessibility - ASSETS '17, ACM Press, 220-229. 